Revista de Antropología Social

ISSN: 1131-558X

http://dx.doi.org/10.5209/RASO 59438

\title{
La mirada feminista en el centro de la antropología vasca
}

Esteban, Mari Luz y Jone M. Hernández García (Coords.). 2018. Etnografias feministas. Una mirada al siglo XXI desde la antropología vasca. Barcelona: Ediciones Bellaterra.

El próximo 27 de noviembre de este año 2018 se cumplirán 40 años del comienzo de la docencia en los viejos edificios de Zorroaga en Donostia-San Sebastián, en la entonces recién constituida delegación de la Facultad de Filosofía y Letras de la Universidad de Bilbao - Universidad del País Vasco / Euskal Herriko Unibertsitatea desde 1980 - Las Licenciaturas de Filosofía, Pedagogía y Psicología tenían comunes sus dos primeros cursos y la antropología estuvo presente, por primera vez en la academia vasca, a partir del curso 1979/1980, en el segundo de dichas titulaciones. En 1982 se fundó oficialmente la Facultad de Filosofía y Ciencias de la Educación.

Distintos elementos se articularon para que se diera esa pronta presencia de la antropología en una recién estrenada universidad. Por un lado, la relevancia social de etnólogos vascos como José Miguel de Barandiarán o Julio Caro Baroja; por otro, el inicio en los años sesenta, por parte de antropólogos como Willian Douglass, de estudios sobre el mundo rural vasco desde aproximaciones teóricas más novedosas a las que hasta entonces habían utilizado los autores clásicos. Así, Muerte en Murélaga o Echalar y Murelaga. Oportunidad y éxodo en dos aldeas vascas, se publicaron en inglés en el año 1970 y 1975 respectivamente y en castellano en 1973 y 1977. En ese contexto, el regreso al País Vasco de personas que se habían formado en la antropología en el extranjero (Joxemartin Apalategi, Jesús Azkona, Teresa del Valle y Joseba Zulaika), fue el último y definitivo empujón que posibilitó que la antropología como disciplina se desarrollara con éxito en la UPV/EHU hasta hoy. En 2017, la unión de la Facultad de Filosofía y CC. de la Educación con la antigua Escuela de Magisterio ha obligado a cambiar la denominación del centro y la antropología forma ya parte del nuevo nombre (Facultad de Educación, Filosofía y Antropología).

Este quizá largo preámbulo es necesario para entender mejor la obra que acaba de publicarse y que reúne trabajos de autoras y autores con distintos recorridos en la producción antropológica vasca, porque el auge de la antropología vasca de las últimas cuatro décadas está fuertemente anclado en una mirada crítica que continúa en la búsqueda del origen de las desigualdades en los órdenes sociales y culturales.

Las coordinadoras del volumen, Mari Luz Esteban y Jone M. Hernández García, junto a Margaret Bullen, desarrollan en un artículo que abre el texto una buena descripción de la producción académica de estas cuatro décadas, que comenzó con un estudio que dirigió Teresa del Valle, Mujer vasca. Imagen y realidad (1985). Visto desde la mirada de alguien que ha formado parte de ese recorrido desde el comienzo, veo en la obra que se publica ahora, no solo una producción más sino una especie de palimpsesto de nuevas escrituras sobre otras anteriores que permanecen más o menos visibles. Una prueba de que la Antropología Feminista como especialidad está bien asentada en la UPV/EHU; el Grado de Antropología Social, el Máster de 
Estudios Feministas y de Género, así como el Doctorado en esta especialidad aseguran esa estabilidad.

Los estudios feministas y de género habían comenzado, principalmente en el mundo anglosajón, unos años antes de que Teresa del Valle llegara a la Facultad de Zorroaga, en un contexto vasco marcado por la transición tras el fin de la dictadura franquista; en esa segunda mitad de los años setenta distintos movimientos sociales y políticos tenían un auge y presencia social significativos. El Movimiento Feminista era uno de ellos y entre otras muchas reivindicaciones (aborto, divorcio, sexualidad libre,...) el ansia por el conocimiento y el descubrimiento del porqué de la situación de subordinación de las mujeres era un aspecto central. Esta inquietud ayudó a que muy pronto se reunieran en torno a la profesora un grupo de alumnas y un profesor (Joxemartin Apalategi) deseosas de avanzar en esos nuevos conocimientos que venían de la mano de la antropología.

Las propuestas teóricas, metodológicas y epistemológicas producidas en la antropología feminista a lo largo de los últimos cincuenta años son muchas y variadas y están bien recogidas en obras producidas en castellano (Narotzky, 1995; Méndez, 2007; entre otras). En ese proceso destaca la aparición y utilización del género en la investigación académica. Sobre el género, término y concepto polémico y polisémico, la historiadora del pensamiento feminista y filósofa francesa Geneviève Fraisse (2016) reflexiona sobre los aspectos positivos y negativos de un concepto que es hoy utilizado con profusión tanto por las instituciones como por los medios de comunicación. Sin embargo, de forma bastante general, esa utilización no supone que se use como instrumento de análisis para mostrar lo que no se deja ver fácilmente; es decir, un trabajo de epistemología política para descubrir las relaciones de poder que construyen y sustentan las desigualdades.

En este sentido, solo si se piensa el género lejos del esencialismo y lo permanente y se ve como un proceso que atraviesa hechos, situaciones, seres y cosas, se puede pensar el sexo y los sexos como algo neutro. Desde este planteamiento, el prisma de género puede observarlo todo y transformarse en un "peligro epistemológico", es decir, que nos obliga a reorganizar la manera en que estructuramos nuestros conocimientos.

Señala Fraisse (2016) que la supuesta atemporalidad de los sexos constituye un obstáculo importante para la constitución de un saber y plantea tres momentos de inflexión en la evolución del problema de la indiferenciación / confusión de los sexos. El primero lo sitúa en 1800, cuando los médicos filósofos superpusieron los seres mujeres/hombres a las cualidades femenino/masculino; el segundo, en 1900, cuando la sociología (antropología) y el psicoanálisis permitieron disociar los seres sexuados de sus cualidades sociales; y el tercero, en 2000, al ser puestos en tela de juicio las dualidades y los binomios, para ser considerados múltiples y dinámicos.

Este proceso ha atravesado dos siglos y se abre al siglo XXI con nuevos y difíciles retos para abordar el análisis de las realidades sociales, el origen de las desigualdades y el dominio masculino, que persiste a pesar de los avances que se han dado en la equidad. Si el género no es lo que somos sino lo que hacemos (Stolcke, 2003), la etnografía sigue proporcionando una buena herramienta para aproximarnos a contextos espaciales y temporales concretos en los que observar tanto las instituciones y las ideologías que las sustentan, como las resistencias que a las estructuras sociales y culturales les plantean la agencia corporal y emocional de las y los sujetos. 
Como ejemplo de las aproximaciones que se están haciendo en la actualidad, el libro que estamos presentando ofrece, además del artículo de presentación al que se ha hecho alusión, quince temas que las coordinadoras han organizado en cuatro apartados. En el primero de ellos, "Nuevas perspectivas de temas clásicos", se abordan objetos de estudio relacionados con los bailes juveniles en el franquismo (Altuna Etxeberria); la participación festiva y la performance de género en la tamborrada donostiarra (Bullen); el cambio en el mundo rural actual y los nuevos modelos de organización territorial (Urquijo Arregui), y el bertsolarismo -improvisación de versos en euskara-, a partir de la importancia del cuerpo en la producción de la palabra (Hernández García).

Un segundo apartado, "Fisuras en los muros: agencia, resistencias y políticas públicas", recoge cuatro trabajos. El primero se sitúa también en el contexto del franquismo y la experiencia de las mujeres ingresadas en manicomios (Martín Zapirain); el segundo, en otra institución como las cárceles y la agencia de las mujeres encarceladas en ellas (Ruiz Torrado); el tercero de los temas gira en torno a nuevas lecturas y culturas alternativas de la menstruación (Guilló Arakistain); esta sección se cierra con una reflexión desde la antropología de las políticas públicas para la igualdad (Fernández-de-Labastida Medina).

Un tercer bloque se aglutina bajo el título "Propuestas teórico-metodológicas sobre cuerpo y etnografía". El primero de los temas incluidos aquí reflexiona sobre el concepto de embodiment y sus posibles traducciones y aplicaciones (González Abrisketa y García Grados); la depresión y los procesos de recuperación es el objeto de estudio del segundo capítulo (Zapata Hidalgo); el derecho al placer de las mujeres en los ambientes festivos (Muelas de Ayala) es el último artículo de este bloque.

Bajo el epígrafe "Las relaciones amorosas en el pensamiento feminista del siglo XXI", se reúnen los cuatro últimos trabajos de esta obra. El "amor adolescente" es el objeto de estudio del primero de los trabajos (Fernández Rodríguez); de la geografía amorosa y la influencia del pensamiento romántico en algunos hombres vascos trata el segundo (Altuna Ramírez); sobre las relaciones de pareja, observadas desde prismas diferentes, así como su importancia en las biografías personales gira el contenido del tercer capítulo de este apartado (Aguirre Miguélez); esta sección concluye con un texto que extiende y reclama ir más allá del estereotipo del amor romántico centrado en la pareja, para abordar la importancia de las relaciones de amistad y las que denomina "comunidades o redes de apoyo mutuo" (Esteban).

La organización de las lecturas en estos cuatro apartados está muy bien diseñada, ya que aglutinan temáticas que están estructuradas bajo criterios que quedan bien expresados en la introducción que las coordinadoras del volumen hacen en cada uno de ellos. Lo interesante, tras la lectura de las aportaciones, es que aparecen hilos que atraviesan y entrelazan muchas de las propuestas. Por supuesto, el cuerpo y las emociones son elementos que recorren de una u otra manera toda la obra, pero no dudo que las futuras y esperemos que futuros lectores encontrarán también otras interrelaciones y sugerencias.

Personalmente, he descubierto nuevas pautas para observar el sistema de relaciones de género en el franquismo a través del control de los cuerpos en los bailes juveniles y en los de las mujeres recluidas en manicomios, por negarse a cumplir los mandatos de género vigentes en la época. El silencio, la exclusión y la violencia han estado y siguen estando presentes en la experiencia de las mujeres bertsolaris, o de las mujeres encerradas en manicomios o en cárceles; las fiestas es otro espacio tradi- 
cional de exclusión y la reivindicación de esos espacios, de gran importancia simbólica, se ha convertido en ocasiones en un verdadero "campo de batalla" que dura ya demasiados años (Bullen y Egido, 2004). En relación a las fiestas, las batallas se están dando, como se muestra en dos de los artículos de este libro, en distintos frentes; uno de ellos es la reivindicación de la participación en igualdad y en la posibilidad de ocupar esos espacios sociales, políticos y simbólicos; el otro, y no menos importante, es el del derecho a vivir la fiesta en plenitud, libre de violencias y a poder disfrutar del placer dejando atrás temores que controlan y limitan la libertad de las mujeres.

Esta obra coral contiene voces que tienen ya tras de sí un importante recorrido intelectual; algunas aportaciones son retazos de tesis doctorales defendidas en los últimos años, mientras otras son avances de tesis que se están realizando en la actualidad. En resumen, un conjunto que muestra el dinamismo actual y las posibilidades de futuro de un proyecto que hunde sus raíces en una tierra bien abonada. La antropología vasca actual no se entiende si no se tiene en cuenta la aportación de la antropología feminista producida en el País Vasco; Etnografías feministas es una muestra de que la antropología hecha en casa puede trascender lo local a través de la elección de objetos de estudio novedosos e interesantes.

Carmen Diez Mintegui Universidad del País Vasco / Euskal Herriko Unibertsitatea (UPV/EHU) c.diez@ehu.eus

\section{Bibliografía}

Bullen, Margaret; Egido, José Antonio (2003). Tristes espectáculos: las mujeres y los Alardes de Irun y Hondarribia. Bilbao: Servicio Editorial Universidad del País Vasco.

Del Valle, Teresa et al. (1985). Mujer Vasca. Imagen y realidad. Barcelona: Anthropos.

Douglass, William (1973). Muerte en Murélaga. El contexto de la muerte en el País Vasco. Barcelona: Barral.

- (1977). Echalar y Murélaga. Oportunidad y éxodo en dos aldeas vascas. San Sebastián: Auñamendi.

Fraisse, Geneviève (2016). Los excesos del género: Concepto, imagen y desnudez. Madrid: Cátedra

Méndez, Lourdes (2007). Antropología feminista. Madrid: Síntesis

Narotzky, Susana (1995). Mujer, mujeres, género. Una aproximación crítica al estudio de las mujeres en las ciencias sociales. Madrid: CSIC

Stolcke, Verena (2003). "La mujer es puro cuento: la cultura del género". Quaderns de l'Institut Catalá d'Antropologia, 19:69-95. 